\title{
A REPRESENTAÇÃO DA FOME EM HOMENS E CARANGUEJOS DE JOSUÉ DE CASTRO
}

\author{
José Aroldo da Silva ${ }^{1}$
}

\begin{abstract}
RESUMO: Este trabalho resultará do estudo da temática da fome, presente no romance Homens e Caranguejos, de Josué de Castro, relacionada com o mundo real. Através de uma pesquisa qualitativa serão consultados documentos de órgãos governamentais e nãogovernamentais, dados estatísticos, matérias de jornais e obras que tratam de questões como a fome, seca e o êxodo rural para subsidiar a análise dos excertos, retirados do corpus, pertinentes ao tema, os quais serão interpretados a partir do método dialético em associação com o método comparativo, sob o enfoque da Teoria do Romance de Georg Lukács, seqüenciada por estudiosos como Lucien Goldmann (Sociologia do romance), Roger Bastide (Arte e sociedade), Michel Zéraffa (Romance e sociedade), Fredric Jameson ( $O$ inconsciente político: a narrativa como um ato socialmente simbólico), Alfredo Bosi (História concisa da literatura brasileira) e Antonio Candido (Arte e Sociedade).
\end{abstract}

PALAVRAS-CHAVE: Fome · Êxodo Rural · Representação literária

RESUMEN: Este trabajo resultará del estudio de el temático del hambre, del regalo en Homens e caranguejos, de Josué de Castro, relacionados con el del mundo real. Con uno que busca cualitativo sea documentos consultados de los cuerpos gubernamentales y de los datos nogubernamentales, estadísticos, de las sustancias periódicas y de los workmanships que se ocupan de preguntas como el hambre, se seca y el éxodo agrícola para subvencionar el análisis de los extractos, quitado de la recopilación, pertinente al tema, que será interpretado del método del dialético en asociación con el método comparativo, bajo acercamiento de la teoría del romance de Georg Lukács, ordenado para estudioso como Lucien Goldmann (sociología del romance), Roger Bastide (Arte y sociedad), Michel Zéraffa (Romance y sociedad), Fredric Jameson (EI político inconsciente: la narrativa como un acto social simbólico), Alfredo Bosi (Historia sucinta de la literatura brasileña) y Antonio Candido (Arte y sociedad).

PALABRAS CLAVE: Hambre • Éxodo agrícola • Representación literária

\section{INTRODUÇÃO}

A fome afeta atualmente 1,02 bilhão de pessoas, quase um sexto da população mundial, segundo um relatório da FAO, a agência da ONU para a Agricultura e a Alimentação. A maior parte das pessoas desnutridas se encontra na região Ásia-Pacífico - 642 milhões, seguida da África subsaariana 265 milhões, América Latina - 53 milhões e da região que compreende o Oriente Médio e o norte da África - 42 milhões. Nos países desenvolvidos, 15 milhões de pessoas sofrem com a fome. Observa-se que nenhuma nação está

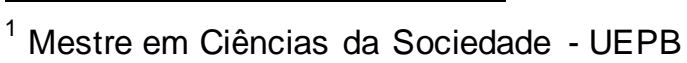


livre da fome, porém é a população dos países pobres que mais sofre com esta calamidade.

Josué de Castro, em seu livro Geopolítica da fome: ensaio sobre os problemas de alimentação e de população do mundo, faz os seguintes questionamentos sobre a fome no mundo: "Será a calamidade da fome um fenômeno natural, inerente à própria vida, uma contingência irremovível como a morte? Ou será a fome uma praga social criada pelo próprio homem? (CASTRO, 1961, p. 45). "A fome e a guerra não obedecem a qualquer lei natural. São, na realidade, criações humanas" (CASTRO, op. cit., p. 63).

Para Josué de Castro "Está provado que a natureza não é mesquinha e que seus recursos são mais do que suficientes para alimentar todo o efetivo humano por longos anos a vir' (CASTRO, 1960, p. 31). Nascido no Recife e graduado em medicina pela Universidade do Brasil em 1929, hoje Universidade Federal do Rio de Janeiro - UFRJ, logo nos primeiros anos de formado, entendeu que a fome estava presente na vida de grande parte da população brasileira.

Josué de Castro teve uma profunda influência na vida nacional e grande projeção internacional nos anos que decorreram entre 1930 e 1973. Autor de obras tais como Geografia da Fome, publicada em 1946, na qual faz uma abordagem da insegurança alimentar que assola a população brasileira, principalmente nas regiões Norte e Nordeste e Homens e Caranguejos, em que retrata a história do personagem Zé Luís que desce do sertão para encontrar o mangue, onde se dá "o ciclo do caranguejo. O ciclo da fome devorando os homens e os caranguejos" (p. 8). Josué de Castro dedicou o melhor de seu tempo e de seu talento para chamar a atenção para o problema da fome e da miséria que assolavam e que, infelizmente ainda assolam, o mundo.

No Brasil, segundo dados do Instituto Brasileiro de Geografia e Estatística - IBGE, trinta e dois milhões de brasileiros - nove milhões de famílias - defrontam-se diariamente com o problema da fome. Existe um desencontro geográfico entre a existência dos produtos e a localização das famílias mais necessitadas. Quase $90 \%$ da produção localizam-se no Sul, Sudeste e porção meridional do Centro - Oeste, enquanto $60 \%$ dos famintos habitam no Norte e Nordeste. 
A primeira pesquisa sobre Segurança Alimentar feita pelo IBGE, como suplemento da PNAD - Pesquisa Nacional por Amostra de Domicilio revelou que quase 14 milhões de brasileiros, ou $7,7 \%$ da população, viviam em domicílios nos quais a fome esteve presente ao menos um dia em 2004.

Os 14 milhões de pessoas vulneráveis à fome representam menos de um terço dos 44 milhões usados como base para a implantação do Fome Zero. O cálculo indireto, a partir da renda, levou em conta linha de pobreza definida a partir de dados da Pnad-IBGE. Nesta pesquisa, a avaliação é direta, mensurada a partir da percepção dos entrevistados sobre sua segurança alimentar.

\section{FUNDAMENTAÇÃO TEÓRICA-METODOLÓGICA}

Para se realizar este trabalho, cujo objetivo é estudar a representação da fome na obra de ficção Homens e Caranguejos, utilizou-se a dialética interpretação/explicação, comparando-se o tema da fome, presente na citada obra de ficção, em relação com o mundo real. A amostragem definida para a pesquisa é composta pelo romance Homens e Caranguejos, de Josué de Castro, no qual está patente a temática da fome.

Os dados que serviram para se fazer uma relação da fome na obra Homens e Caranguejos com a fome do mundo real serão coletados a partir de uma pesquisa de campo em que foram consultados documentos de órgãos governamentais e organizações não-governamentais, dados estatísticos, matérias de jornais que tratem do tema fome, seca, ausência de políticas públicas de geração de trabalho e renda e, conseqüentemente, movimento de populações e outras informações voltadas para este fenômeno social, a fome.

Do romance Homens e Caranguejos, foram retirados excertos relacionados com os temas: fome, seca, migração rural, descaso do governo, nas esferas municipal, estadual e federal, quanto a uma política de convivência com os efeitos das estiagens e ausência de políticas públicas capazes de gerar trabalho e renda para a população que vive no sertão nordestino. 
Esses excertos foram analisados sob o enfoque da sociologia do romance, teoria de Georg Lucáks, defendida por estudiosos como Lucien Goldmann, Michel Zéraffa, Roger Bastide, Fredric Jameson, dentre outros, aplicando-a ao tema fome, patente na obra Homens e Caranguejos, objetivando demonstrar dialeticamente com excertos de jornais, documentos de órgãos do governo e de entidades não-governamentais e dados estatísticos, pertinentes ao assunto, que a temática da fome não é mera criação do ficcionista Josué de Castro e sim, a transposição do cotidiano de uma realidade mundial, brasileira e nordestina para o plano da literatura.

O quadro teórico de referência que deu o suporte analítico ao presente estudo sobre o fenômeno da fome na obra de ficção Homens e Caranguejos e suas relações com o mundo real, fundamentar-se-á na sociologia do romance enunciada por Georg Lucáks, teórico de formação marxista, em seu livro $A$ teoria do romance, retomada por Lucien Goldmann, Roger Bastide, Michel Zéraffa, Antonio Candido e Alfredo Bosi, estudiosos da teoria desenvolvida pelo sociólogo húngaro, tendo Alfredo Bosi, adaptado-a ao romance brasileiro de trinta, adjetivando-os de romances de tensão crítica.

Nestes romances classificados por Bosi (1996) como de tensão crítica, constata-se que a arte literária de fundo social tem como finalidade veicular uma denúncia social. Assim sendo, a teoria apresentada por Georg Lucáks permite estudar estes romances partindo da premissa de que a literatura produzida por ficcionistas como Josué de Castro possuem homologias do ficcional com o mundo real, pressuposta por Goldmann em seu livro $A$ sociologia do romance em que diz que o dado inicial para analisar o romance é partir da tensão entre o escritor e a sociedade.

Trabalhou-se para explicar a relação da fome presente no romance Homens e Caranguejos em sua relação com o cotidiano real da sociedade do Nordeste brasileiro, recorrendo-se ao conceito de herói problemático, em Lucáks (2000), retomado por Goldmann (1976) como herói demoníaco, personagem criado pelo escritor para veicular a busca degradada de valores autênticos em uma sociedade degradada, a relação de arte e sociedade, ou seja, a obra de arte como reveladora do mundo real e as homologias entre a estrutura da obra literária e a estrutura social. 
A teoria lukacsiana pode ser atualizada com os estudos de Fredric Jameson, que é considerado a figura central da crítica literária marxista nos Estados Unidos. Autor de obras tais como: Postmodern or, The cultural logic of late capitalism, Marxism and form (Pós-modernismo: a lógica do capitalismo tardio, marxismo e forma), escreveu também The political uncounscios. Narrative as socially simbolic act (O inconsciente político: a narrativa como ato socialmente simbólico), livro no qual Jameson defende a historicidade da narrativa, que segundo ele deve ser reencontrada a partir de um inconsciente político.

As argumentações de Jameson, no que diz respeito à interpretação política da narrativa, amparada no reconhecimento de um inconsciente político, atualizam a teoria luckacsiana, uma vez que amplia a análise do romance da perspectiva da existência de um herói problemático, o qual trava uma luta individualista por valores autênticos em uma sociedade degradada, para um projeto de salvação que parte de uma busca coletiva com o indivíduo reconhecendo que, na verdade, tudo, em última análise é político.

\begin{abstract}
A defesa de um inconsciente político propõe que compreendamos justamente essa última análise final e exploremos os múltiplos caminhos que conduzem à revelação dos artefatos culturais como atos socialmente simbólicos. (JAMESON, 1992, p. 18).
\end{abstract}

A interpretação política proposta por Fredric Jameson parte do princípio de que o homem faz parte de uma única grande história coletiva, a história da luta de classes. O inconsciente político que Jameson defende como necessário para a explicação da narrativa só encontra sua função e sua necessidade quando se detectam os traços dessa narrativa ininterrupta, ou seja, quando a uma conscientização de que a sociedade é o palco para a luta de classes, na qual aparece o confronto entre opressor e oprimido.

\title{
Literatura de 30 no Nordeste
}


O romance Homens e Caranguejos, publicado por Josué de Castro em 1966, apresenta características peculiares ao chamado romance de 30 no Nordeste, que por meio de escritores como Graciliano Ramos - Vidas secas; José Américo de Almeida - $A$ bagaceira e Raquel de Queiroz - O quinze, dentre outros autores representativos desse período, retrataram a vida da população nordestina que vive sob as intempéries da seca e a calamidade da fome e do êxodo rural.

Habitando uma região em que o clamor do povo não era ouvido no resto do Brasil, dada a situação de dominação e alienação a que estava submetida a população, os escritores, a exemplo, de José Américo de Almeida, José Lins do Rego, Raquel de Queiroz e Graciliano Ramos, considerados escritores regionalistas, serviram, através de suas obras literárias, como denunciadores das condições de vida a que eram submetidos milhares de nordestinos.

A denominação romance de intervenção social dada à produção literária do período compreendido entre 1930 e 1945 no Nordeste vem certamente desse engajamento dos romancistas com o objetivo de promover uma denúncia das circunstâncias em que vivia uma parcela da população brasileira. Como afirma Abdala Júnior (1993, p. 11), esses prosadores regionalistas,

Não escrevem apenas como forma de provocar estesia, o prazer artístico, mas também como uma maneira de conscientizar o leitor de problemas reais de seu tempo. $O$ romance é para eles, pois, de intervenção social: o objetivo comum era criticar ou denunciar um problema social para contribuir para a sua solução.

A fome, calamidade que assola parte da população mundial, constatada através de pesquisas de órgãos governamentais e instituições internacionais, permeia obras da literatura de 30 no Nordeste. Ficcionistas como Raquel de Queiroz em $O$ quinze e Graciliano Ramos em Vidas secas retrataram a calamidade da fome em suas obras conforme se pode observar nos excertos, 
Vicente contava agora a história de uma mulher conhecida que endoidecera, quando viu os filhos morrendo à falta de comida. Dona Inácia observou: Talvez tenha enlouquecido também de fome. Fome demais tira o juízo (O QUINZE, p. 81).

E ainda,

Coitado, morrera na areia do rio, onde haviam descansado, à beira de uma poça: a fome apertara demais os retirantes e por ali não existia sinal de comida (VIDAS SECAS, p. 11).

A temática da fome está, também, presente no romance Homens e Caranguejos. "Só a fome continuava a mesma. [...] A fome foi crescendo na minha barriga vazia. A boca foi ficando cheia de uma saliva impertinente" (CASTRO, 2003, p. 48).

A miséria e a fome que castigam o nordestino aumentam quando a população é a que está inserida na região semiárida do Nordeste, área mais castigada pelas estiagens. Para corroborar esta afirmação, recorre-se ao Jornal Correio da Paraíba, na edição de 05 de janeiro de 2003, em seu caderno Cidades, na página $\mathrm{B}-1$, em matéria intitulada $A$ miséria na $P B$, quando relata que: Do litoral ao sertão paraibano a miséria e a fome estão presentes, mas a situação é mais dramática nas regiões que sofrem com a ausência de chuvas. Ou seja, a pobreza segue mais ou menos, a trilha da seca, em regiões do semiárido paraibano.

Conforme pesquisas realizada pelo Instituto Brasileiro de Geografia e Estatística - IBGE, em 2004, cerca de 72 milhões de pessoas - 39,8\%, estão vulneráveis à fome em maior ou menor grau. Vale ressaltar que mais da metade - $52 \%$, da população afetada pela fome vive no Nordeste, e que o Maranhão é o Estado com maior percentual de lares com esse problema $(18 \%)$. 


\section{A Leitura do Texto Literário}

Sabe-se que é possível realizar-se a leitura do texto literário a partir de uma fundamentação e/ou fundamentações teóricas associadas à história, à sociologia, à geografia, dentre outras ciências. Tratando especificamente do livro Homens e Caranguejos, do médico Josué de Castro, observa-se que o autor buscou nas temáticas do êxodo, e da exploração do homem pelo homem, mostrar por meio da literatura de ficção uma realidade que assola milhões de pessoas no mundo, a fome.

A pesquisa a que se propôs este trabalho resultou, pois, do seguinte problema: as obras literárias, de fundo social, têm o mundo real como referente e, como se sabe a fome é causado pela seca e pela falta de ações administrativas governamentais que gerem emprego e renda no campo, garantindo a permanência do nordestino em seu meio, pergunta-se: quais os fatores causadores da fome representada no romance Homens e Caranguejos de Josué de Castro?

Para orientar a pesquisa apresentou-se uma problematização para o tema, objetivando-se estudar a representação da calamidade da fome na obra Homens e Caranguejos, mostrando as causas e conseqüências que transformam o homem do mangue em faminto, trabalhando com a hipótese de que a fome apresentado na obra, Homens e Caranguejos, é uma criação humana.

\section{CONSIDERAÇÕES FINAIS}

É necessário tomar-se conhecimento da realidade política, econômica e social do Brasil de ontem para que seja possível o entendimento do Brasil de hoje. Pode-se buscar essa compreensão nos escritos literários, romances de um período histórico e literário, uma vez que a literatura, partindo de um fato do cotidiano, consegue transformá-lo em ficção, transpondo a realidade para o plano literário. 
O fenômeno da fome, transformado em ficção por Josué de Castro, em sua obra Homens e Caranguejo, nos chamou a atenção, despertando o interesse de investigá-lo, explicá-lo e compreendê-lo quanto ao tema fome contido em seu enredo, o que SE constituiu o objeto de estudo da pesquisa desenvolvida.

O tema da fome, que norteia a obra Homens e Caranguejos, não é criação da imaginação do ficcionista Josué de Castro e sim a transposição da vida cotidiana de uma realidade mundial, brasileira e nordestina, para o plano da literatura, o que se constitui como extrapolação do plano meramente literário.

A presente pesquisa tem sua importância acadêmica, uma vez que dará contribuições à teoria e crítica literárias e sociologia do romance, mostrando a possibilidade de se estudar a obra literária não apenas com uma fundamentação teórica concentrada na literatura, mas buscando outras áreas do conhecimento para explicar fenômenos que tematizam os romances de tensão crítica, de fundo social, os quais são escritos, com seus autores partindo de fatos sociais, o que reforça a contribuição da literatura para 0 estudo da história, da sociologia, da geografia.

\section{REFERÊNCIAS BIBLIOGRÁFICAS}

A MISÉRIA na PB. Correio da Paraíba, Campina Grande, 05 jan. 2003.

BASTIDE, Roger. Arte e sociedade. 2 ed. São Paulo: Companhia Editora Nacional, Editora da USP, 1971.

BERGER, Peter e LUCKMANN, Thomas. A construção social da realidade. 4 ed. Petrópolis: Vozes, 1978.

BOSI, Alfredo. História concisa da literatura brasileira. 35 ed. São Paulo: Cultrix, 1996.

CANDIDO, Antonio. Literatura e sociedade. São Paulo: Cia Editora Nacional, 1965. 
CASTRO, Josué de. Geografia da fome: O dilema brasileiro; pão ou aço. Rio de Janeiro: Civilização Brasileira, 2001.

CASTRO, Josué de. Geopolítica da fome: ensaio sobre os problemas de alimentação e de população do mundo. 6. ed. São Paulo: Brasiliense, 1961.

CASTRO, Josué de. Homens e caranguejos. Rio de Janeiro: Bertand Brasil, 2003.

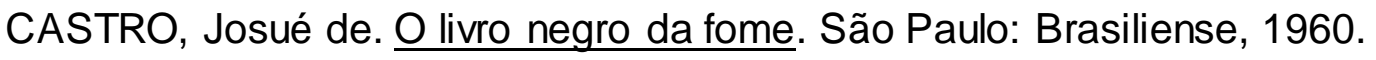

CERTEAU, Michel. A invenção do cotidiano: artes de fazer. 6. ed. Petrópolis: Vozes, 2001.

ECO, Umberto. Interpretação e superinterpretação. São Paulo: Martins Fontes, 2001.

Editora, 1978.

FARIA, Ângela Caldas Sanábio. Homens e caranguejos: uma trama interdisciplinar. A literatura topofílica e telúrica. Dissertação apresentada ao Mestrado em Letras do Centro de Ensino Superior de Juiz de Fora. Juiz de Fora: Centro de Ensino Superior de Juiz de Fora, 2008.

FOUCAULT, Michel. A ordem do discurso. São Paulo: Edições Loyola, 2001.

GARBUGLIO, José Carlos. Fôlego de gato (o regionalismo e suas versões). In: Ata semiótica e lingüística. São Paulo: Global Editora, vol. 3, 1979.

GARCIA, Carlos. O que é Nordeste brasileiro. 5. ed. São Paulo: Brasiliense, 1986.

GOLDMANN, Lúcien. A sociologia do romance. Rio de Janeiro: Paz e Terra, 1988.

JAMESON, Fredric. O inconsciente político: a narrativa como um ato socialmente simbólico. São Paulo: Ática, 1992.

LUCÁKS, George. A teoria do romance.São Paulo: Duas Cidades; Editora 34, 2000.

MORAES, Maria Célia Marcondes de. História, narrativa e interpretação: aproximações ao pensamento de Fredric Jameson. In: Revista brasileira de história. São Paulo: ANPUH, Contexto, vol. 16, n.ํㅜ 31-32 1986.

QUEIROZ, Raquel de. O quinze. 16. ed. Rio de Janeiro: José Olympio Editora, 1973.

RAMOS, Graciliano. Vidas secas. 76. ed. São Paulo, Record, 1998. 
REIS, Carlos e LOPES, Ana Cristina M. Dicionário de Teoria da narrativa. São Paulo: Ática, 1988.

TELLES, Gilberto Mendonça. A crítica e o romance de 30 no Nordeste. In: $\underline{0}$ romance de 30 no Nordeste. Fortaleza: PROED, 1983.

TERTULIAN, Nicolas. Lukács hoje. In: Lukács e a atualidade do marxismo. São Paulo: Boitempo Editorial, 2002.

ZÉRAFFA, Michel. Romance e sociedade. Lisboa: Estúdios Cor, 1974. 